\title{
Changes in Management Control Systems and Diffrential Impact on Performance: A Test Modeling
}

\author{
Khalifa Ahsina \\ Dept. of Management, Ibn Tofail University \\ PO Box 2010, Kenitra, Maroc \\ Tel: 212-675-789-297Ｅ-mail: k_ahsina@yahoo.fr
}

Received: November 14, 2012 Accepted: November 22, 2012 Published: December 31, 2012

doi:10.5296/bms.v3i2.2937 URL: http://dx.doi.org/10.5296/bms.v3i2.2937

\begin{abstract}
This article aims to present the main results of an empirical study done in Morocco and attempts to highlight:

- What explains the variety of practices in management control?

- And what is the impact of adopting these practices of management control systems on corporate performance.

To begin, a brief review of the literature allow us to better define the problem of our research is in the field of contingency theory.

In a second step, we present the methodology of our investigation and the variables that can explain the changes of management control systems. Finally, we present the main results of the research.
\end{abstract}

Keywords: Management control, Contingency theory, Organizational performance 


\section{Introduction}

This research aims to explain the changes in management control systems by providing some answers to the two theoretical questions: What explains the variety of practices in management control? And what is the impact of adopting these practices of management control systems on corporate performance. Answering these questions involves using a theoretical framework that provides a list of determinants and an indication of the direction of the impact of these determinants. We discuss in terms of contingency theory. This perspective has provided a coherent paradigm for the analysis of organizations (Donaldson, 2001) and is the mainstream of the study of control systems (Covaleski et al., 1996). The article presents the first part, a brief review of the literature. The second part of the research design chosen to explain this variety. In the third and final part, the presentation of the results will be achieved. However, it should overshadow some limitations, and avenues of research.

\section{Main Determinants of Management Control Systems}

Many definitions and typologies of management control have been proposed. In fact, its traditional design based on budgetary control and adapted to stable environments tend to evolve towards a proactive management control, also called "new management control." Indeed, the evolution of concepts of management control, we find that it plays a much more active role in the realization of the strategy defined by the organization. Two important points are highlighted with one hand, the necessary relationship between strategy and management control and secondly, that the control is not limited to the process of comparing results with objectives.

Thenet Gervais (1998) and others have sought to redefine the roles of budgetary control when confronted with increased turbulence. This is the nature of budgetary control is changed. We spend a design for the allocation and control of resources in a more control oriented. Indeed, in a changing environment, effective strategies tend to emerge from a series of decisions often initiated by intermediate executives in contact with the markets and technologies. In 1987, Robert Simons emphasizes the relationship between strategy and control since the nature of systems and control processes can not be separated from strategic considerations. The author draws on the typology of Miles and Snow (1978) with prospectors and defenders thus highlighting the correlation between the control systems implemented and developed the type of strategy and performance. The leader focuses its attention on activities with high strategic uncertainties. Beyond the choice of a business strategy, leaders must adopt a strategy control. Simons then distinguishes programmed controls interactive controls requiring management involvement. 


\subsection{The Influence of Variable Strategy}

Today, the strategy is a contingency factor that plays a growing role in the explanation of the control systems (including the budget) (Bouquin, 2000, Dent 1990; Langfield-Smith, 1997).

In general, you can see the strategy as a position (that is to say content) or as a process (how it is constructed and completed) (Mintzberg et al., 1999). There are two levels of strategy: the strategy of "corporate" strategy and "business". Here we focus only on the strategy of "business" as determinants of fiscal systems, it is indeed in this area that most of the research on the link / control strategy are (Langfield-Smith, 1997).

Three types of operationalization of the strategy research contingent strategy / control have been proposed by the positioning of the mission or the typology of Miles and Snow (1978). The three types are sometimes described as quasi-equivalent (eg Van de Stede, 2001).

Conclusions of this work ensued the following hypothesis.

$\mathrm{H}$ 1: "Companies have prospectrices budgetary control and interactive defendants budgetary control diagnosis".

\subsection{The Influence of Variable Profile Controller}

In the bureaucratic function, the management controller was primarily responsible for the definition of management control system (definition of the nature and form of comparisons to be made ....) and the provision of policy makers predefined management information. Indeed, Chiapello E (1990) showed that the traditional management control was more the preserve of older controllers, while the board was more common among young graduates, the researcher interprets as a dream of young, in which the weariness ends after many years of hard practice to give way to management control technician.

It would be interesting to do a test on the variable "age" as the search Chiapello is made in a French context.

Conclusions of this work ensued the following hypothesis.

H 2: "The technical profile is found in the Diagnostic Management Controller and the profile manager is found in the Interactive Management Controller". 
2.3 The Influence of Variable Complexity of the Organization

The complexity of organizations is one of the arguments used by Johnson and Kaplan and Kalika (1987).

These results confirm the findings of Bruns and Waterhouse (1975) observe that more sophisticated budgeting practices are found in the most decentralized structures.

Merchant (1981) also reaches the same conclusion by showing that the budget process is more formalized, more complex, and more participatory in the most decentralized organizations. Conclusions of this work ensued the following hypothesis.

H3: "organizations more differentiated and decentralized structural feature systems planning and control most developed".

\subsection{The Influence of Variable Size}

Merchant (1981) observe that more sophisticated budgeting practices are found in the most decentralized structures. Merchant (1981) also reaches the same conclusion by showing that the budget process is more formalized, more complex, and more participatory in the most decentralized organizations. Conclusions of this work ensue the fourth research hypothesis:

H4: "The larger a company is, the greater management control may emerge and grow".

\subsection{Emergence of Control and Impact on Performance}

Management control is born in 1920 at General Motors (GM). Indeed, Sloan, after finding weaknesses in the organization performed under the direction of its predecessor, trying a new organization.

Very soon, the new approach produced remarkable effects. Thus in 1925, the gap between expectations and achievements do not exceed 1\%. The market shares of Ford and GM are reversed between 1920 and 1940, while Ford holds 55\% in 1921 in the U.S. market against 12\% for GM. They pass in 1940 to $47.5 \%$ against $18.9 \%$ for Ford, GM and became the largest and most profitable company in the world.

In fact, multiple studies have followed since the seventies to understand the impact of budgetary practices on performance.

H5: Firms that have implemented a system of management control are more successful than those without control system ". 
2.6 Influence Differentiated Management Control Systems Performance

Traditional management control, which simply highlight differences between forecasts and realizations, and focuses exclusively on the financial aspect, does not participate effectively in adaptation efforts of the firm to its environment.

In contrast, the Controlling Interactive is looking to the future, open to opportunities not exclusively financial, and especially more adaptable to the needs of managers. Thus, it is likely to help them in their strategic decisions or daily. Conclusions of this work ensued the last two research hypotheses.

H6: "Companies that have implemented an interactive control are more successful than those that have a control system diagnostic".

The objective of this first point was to investigate the impact of contingency factors on management control.

After reviewing the literature, we have constructed a theoretical model as follows:

\section{Our research model}

\section{types of environments}

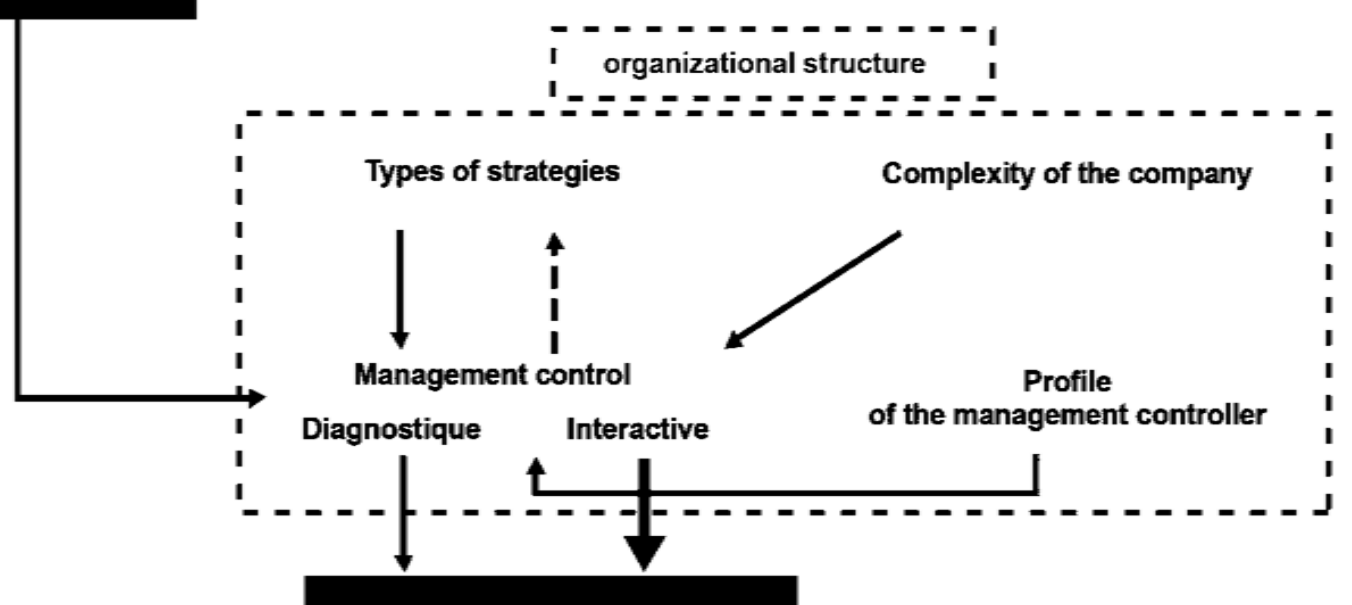

Organizational performance

\section{Methodological Aspects}

The methodology of this research could thus be described as quantitative methodology. Six hypotheses have been proposed in the model. The data collected have corroborated the theoretical model as a whole. 
So, we conducted a survey of 35 Moroccan companies to test our model. The results of this research have enabled us to validate our theoretical model part

This questionnaire includes a variety of questions and is divided into four parts. The questionnaire was sent to a sample of 400 firms. He was sent to the heads of management control.

The questionnaire was sent by mail, with a letter of introduction in which the optical search was specified.

\section{The Empirical Results}

The system of management control means does not exist, a detailed analysis of the responses allows us to differentiate practices according to the following criteria:

\subsection{The Profile of a Management Controller}

Therefore, the Controller is a man, thirties, attached to financial management, working in large part in companies with more than 500 people higher education Bachelor type of study over four years in management or accounting and who its assets under five years of activity within the company.(See table 1)

\begin{tabular}{|l|l|l|}
\hline \multicolumn{1}{|c|}{ criteria: } & \multicolumn{1}{|c|}{ Score ++} & \multicolumn{1}{c|}{ Score -- } \\
\hline Sex : & $86 \%$ male & $14 \%$ female \\
\hline Age : & $82 \%$ were under 35 years & $18 \%$ were over 35 years \\
\hline Origin of recruitment: & $69 \%$ recruited internally & $31 \%$ recruited externally \\
\hline Seniority in the post & $55 \%$ were under 5 years & $45 \%$ were over 5 years \\
\hline Basic Training: & $\begin{array}{l}73 \% \text { trained in finance and } \\
\text { accounting }\end{array}$ & $27 \%$ are engineers \\
\hline Level of training: & $91 \%$ have a Bachelor level & $\begin{array}{l}\text { 9\% have a level of less than } \\
\text { Bachelor }\end{array}$ \\
\hline Affiliation: & $45 \%$ are related to the CEO & $\begin{array}{l}55 \% \text { are linked to the } \\
\text { Finance Department }\end{array}$ \\
\hline
\end{tabular}

Table 1. The profile of a management controller

\subsection{The Three Dimensions of Differentiation Control Systems Management}

From table 2, we see that the difference between management control interactive clear at the first three-dimensional systems and interactive control, there's a constant involvement of managers in the management of operational, so it there's a strong link between the budget and plan. There is also a strong involvement in the construction of operational budgets. 


\begin{tabular}{|l|l|l|}
\hline Dimensions : & Controlling Diagnosis & Controlling Interactive \\
\hline Implication : & $\begin{array}{l}12 \% \text { (management by } \\
\text { exception) }\end{array}$ & $\begin{array}{l}88 \% \text { (constant } \\
\text { involvement) }\end{array}$ \\
\hline Link budget - plan: & $24 \%$ Low & $76 \%$ Strong \\
\hline $\begin{array}{l}\text { Participation in the construction of } \\
\text { operational budgets: }\end{array}$ & $36 \%$ Low & $64 \%$ strong \\
\hline Re forecasting budgets: & $44 \%$ & $56 \%$ \\
\hline $\begin{array}{l}\text { Link between the objectives and } \\
\text { budgetary compensation managers }\end{array}$ & $50 \%$ & $50 \%$ \\
\hline
\end{tabular}

Table 2. The three dimensions of differentiation control systems management

\subsubsection{Influence of Size on the Emergence of Management Control}

It was found that the average number of firms with established control service management is clearly higher than firms without controlling. Controlling the link size and is therefore very clear. (See figure 1)

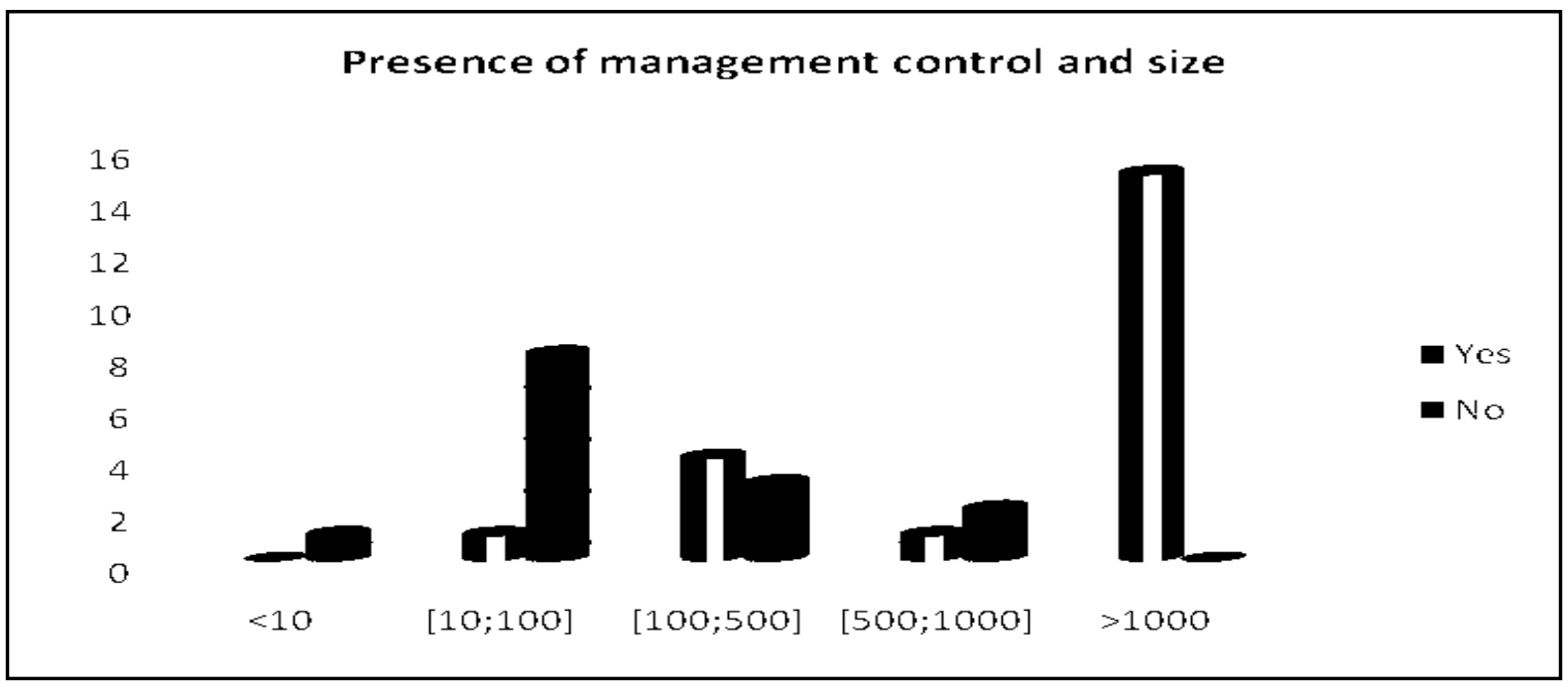

Figure 1. Presence of management control and sise

\subsubsection{Influence of Profile Controller on Differentiation of Management Control}

The factorial map us back $90 \%$ of the information. We note that the profile is accounting manager are closer procedures for control of interactive management and the technical profile (type engineer) is closer to the diagnostic profile. Thus, the hypothesis $\mathrm{H} 2$ is accepted.

\subsubsection{Existence of Systems and Performance of Management Control}

Observation of the map of the MCA, we note that the terms of superior performance are close to the modality "Existence of management control" and that the terms reflect the decline in 
performance is close to the modality "Lack of management control" Thus, we can assume that companies have implemented a management system are more successful than those without management control, therefore, the hypothesis H5 is verified by a confirmatory factor analysis in future work.

\subsubsection{Differentiation of Management Control and Performance}

Different modalities of management control interactive methods are very close to the superior performance, so we can assume that the management control system allows interactive induce superior performance to those of diagnostic control systems. Thus, the hypothesis H6 can be verified by a confirmatory factor analysis.

Using the software SPSS (Statistical Package for the Social Sciences) 17, it was possible to test the nature of relationships that may exist between contingency variables and practices of management control and performance.

In general, the results show the existence of a positive relationship between the complexity of organizations (measured by the size), the emergence and development of management control systems So, the hypothesis H4 is accepted.

So we were able to demonstrate that the establishment and development of control systems provide superior performance businesses.

The profile of the controller, we can say that it has an important role in the differentiation of control systems and a technical profile tends to play a role or traditional diagnosis, while a profile manager is more interaction with operational and therefore more likely to "bring out" new strategic opportunities.

however, the lack of a statistically positive effect between environmental variables and strategy with control systems has been verified without stating definitively the existence of causal link.

\section{Conclusion}

In this article, the explanatory power of our theoretical model has been validated in terms of the empirical world.

Ultimately, we can say that in general, our main results suggest that implementation of management control systems is justified firstly by the complexity of the business.

Indeed, the larger the business becomes large (> 500 people), plus the need for control becomes important and companies tend to implement such systems. 
Similarly, the turbulence of the environment and the profile manager controllers tend to encourage the development of interactive systems management control. Thus, the analysis of empirical data we can see the influence of these two variables on the development of these systems.

Finally, the modernization of control systems has the effect of providing higher performance than firms that use traditional systems of control, any time it must be corroborated by future research.

Two major methodological limits should be highlighted: the modest size of the sample and the use of a perceptual approach to collect data. In this regard, we can have a difference between the responses collected and the real practices.

We used in this research the contingency theory to explain the changes of management system of control. In this context, many avenues of research are considered. Others theories must be also used to explain changes in management control like the model of Rogers.

\section{References}

Anthony R. N. (1988). « The management control function» The Harvard Business Press.

Bollecker M. (2001). «Systèmes d'information différenciés et contrôle des services opérationnels : une analyse empirique des mécanismes organisationnels de contrôle et du rôle des contrôleurs de gestion », Recherche en sciences de gestion, Nancy 2.

Bouquin H. (1998). Le contrôle de gestion, 4e éd., PUF, Paris.

Covaleski, M. A., Dirsmith, M. W. \& Samuel, S. (1996). 'Managerial accounting research: the contributions of organisational and sociological theories'. Journal of Management Accounting Research, 8, 1-35.

Donaldson, L. (2001). The Contingency Theory of Organizations, Sage, Thousand Oaks.

Evrard Y., Pras B., Roux E. et al (1997). « Market : études et recherches en Marketing » Nathan.

Gervais M. et Thenet G. (1998). «Planification, gestion budgétaire et turbulence », Finance, contrôle, stratégie, 1(3), septembre, 57-84.

Gervais M. et Thenet G. (1998). «Planification, gestion budgétaire et turbulence », Finance, contrôle, stratégie, 1(3), septembre, 57-84.

H. Jordan. (1988). «Planification et contrôle de gestion en France en 1988 » H.E.C. 
Langevin P. et Naro G. (2003). « Contrôle et comportements : une revue de la littérature anglosaxone ». Congrès AFC-CCA.

Langevin P. et Naro G. (2003). « Contrôle et comportements : une revue de la littérature anglosaxone ». Congrès AFC-CCA.

Nicolas Berland. (2002). «Fonctions du contrôle budgétaire et turbulence », cahier de recherche. PESOR, Faculté Jean Monnet

Nicolas Berland. «Fonctions du contrôle budgétaire et turbulence », cahier de recherche. PESOR, Faculté Jean Monnet

Patrick BARWISE. (1997). «STRATÉGIE délibérée ET STRATÉGIE ÉMERGENTE : La plupart des stratégies sont le résultat d'un ensemble de décisions émanant souvent de l'encadrement intermédiaire » Les Echos - Vendredi 25 et Samedi 26 avril 1997.

Simons R. (1987). «Implementing strategy: configurations in management control systems ». Meeting of the Strategic Management Society in Boston..

Simons R. (1995). «Levers of control: how managers use innovative control systems to drive strategic renewal ». Boston, Harvard Business School Press.

SPANG Laurent. (2002). «La modélisation de l'évolution du contrôle de gestion dans une organisation : le cas des caisses primaires d'assurance maladie (CPAM) » Recherche de doctorat, Université de Nancy 2. 